\title{
Imagem e narrativa no judaísmo antigo
}

\author{
IVAN ESPERANÇA ROCHA \\ Departamento de História - Faculdade de Ciências e Letras \\ UNESP (Campus de Assis)
}

\begin{abstract}
RESUMO: Este trabalho apresenta uma reflexão sobre a relação entre imagem e narrativa no judaísmo antigo. A proibição de ícones reduziu a representação das características da sociedade israelita à documentação literária. Não obstante, as imagens e símbolos estão presentes na narrativa e exercem um papel fundamental na definição da cultura israelita.
\end{abstract}

PALAVRAS-CHAVE: Iconografia; literatura; judaísmo; Oriente Próximo Antigo.

Caiu, caiu! Babilônia, a Grande, a que embebedou todas as nações com o vinho do furor (Ap 14,8).

A imagem permaneceu durante muito tempo como um objeto, quase exclusivamente, ligado à arte e à história da arte, mas nas últimas décadas sua utilização como fonte para a história é uma prática cada vez mais usual que complementa e enriquece a abordagem de um determinado objeto histórico.

A cerâmica, manuscritos com pinturas, imagens soltas de propaganda política e religiosa, quadros, estátuas, fotografias - ou simplesmente material visual (Gaskell, 1992, p. 238) - ganham uma importância não tanto ligada às suas qualidades estéticas mas à capacidade de representar os imaginários sociais e de evidenciar as mentalidades coletivas (Chartier, 1993, p. 406-7). No estudo das sociedades antigas, a iconografia, neste seu significado mais amplo de material visual, assume um papel de destaque, particularmente, quando não se tem a contrapartida da documentação escrita ou quando esta é lacônica. É o caso, por exemplo, da iconografia funerária ou templária do Egito.

Por incrível que pareça, quando se trata de analisar uma cultura bem próxima daquela egípcia, no espaço e no tempo, não temos acesso a nenhum dado proveniente da iconografia. Estamos nos referindo à cultura israelita antiga, cuja documentação coincide, praticamente, com a do Antigo Testamento do texto bíblico.

No Israel anticotestamentário, um dos mandamentos do decálogo proíbe as imagens: 
Não farás para ti imagem [pesel] esculpida de nada que se assemelhe ao que existe lá em cima, nos céus, ou embaixo na terra, ou nas águas que estão debaixo da terra (Ex 20,4).

Devido a isto, não temos, particularmente no que diz respeito à divindade Israelita, nenhuma efígie de Javé [YHWH] encontrada nas escavações arqueológicas (Von Rad, 1967, p. 143). Porém, esta proibição não se resume à divindade. Ela foi-se tornando cada vez mais abrangente até, praticamente, banir toda e qualquer iconografia de Israel ( $L v 26,1$; Dt 4,16s; 5,8ss; 27,15). Existem exceções mas estão localizadas no judaísmo tardio:

Os grandes mosaicos de Beth Alpha e Ain ed-Duk, nos quais estão representados os símbolos do zodíaco e o sol - no primeiro, também o sacrifício de Isaac, e, no segundo, Daniel na fossa dos leões -, podiam ser considerados como tardias exceções a uma norma tradicional. Podia-se pensar que, no período bizantino, os fiéis da sinagoga tivessem começado a reproduzir imagens bíblicas de outros gêneros para evitar o monopólio cristão de tais representações (Von Rad, 1967, p. 149).

A proibição de ícones inibiu a arte em Israel impedindo a visualização dos traços étnicos e a representação das características da sociedade israelita, que ficam restritos à documentação literária. Na narrativa, no entanto, as imagens e símbolos estão presentes e exercem um papel fundamental na definição da cultura israelita, como acontece em qualquer sociedade tradicional. A narrativa bíblica, mais que um retrato, deve ser entendida como uma representação e uma abstração dos acontecimentos a que se refere. Como diz Todorov, os acontecimentos não existem em si, mas são apercebidos e contados por alguém, sempre a partir de um imaginário (EveraertDesmedt, 1984, p. 4). Como narrativa, ela tem um nível histórico, ou seja, um conteúdo - um conjunto de eventos, personagens e cenários representados -, e um nível do discurso, considerado como os meios de expressão que veiculam e plasmam esse discurso, no qual se inclui a simbologia (Reis e Lopes, 1988, p. 49).

$\mathrm{Na}$ literatura israelita podemos falar de um simbolismo, de um imaginário externo e interno, logicamente, de cunho coletivo, uma vez que a narrativa, ao utilizar códigos e signos exige dos destinatários a aptidão para a decodificação de sua mensagem (Idem, p. 101). O imaginário externo é aquele ligado ao imaginário universal, mítico e místico, como a criação, o dilúvio, os atributos divinos. O interno é aquele ligado a aspectos da cultura israelita, do qual fazem parte fatos significativos, como o Exxodo e o movimento pela terra prometida, personagens fundadores, como Abraão e os patriarcas, e heróis nacionais, como Moisés, alguns juízes, profetas e reis.

A questão do simbolismo bíblico atinge a sua máxima expressão quando todo o Antigo Testamento passa a ser interpretado pelos hermeneutas da escola alegórica, como Clemente de Alexandria (+215) e Eusébio de Cesaréia (+340), como tipo, alegoria do Novo Testamento. Esta interpretação dominou os estudos bíblicos por séculos, impedindo o conhecimento da arquitetura literária presente nos textos bíblicos. Foi somente a partir de fins do século XVIII, que o método histórico crítico começou a ser aplicado à Bíblia, tendo 
como pioneiros os estudos de Lessing (1729-1781), Herder (1744-1803) e Eichhorn (17521827) (Rocha, 1990, p. 13-15).

Uma comparação entre o imaginário judaico interno e externo foi sendo favorecida pela decifração das línguas da documentação do Antigo Oriente Próximo a partir do século passado. Pritchard (1969) elenca mais de 500 possíveis relações entre essa documentação e aquela do Antigo Testamento.

Os estudos críticos foram revelando a extrema heterogeneidade dos textos bíblicos que passam a ser analisados como uma antologia composta a partir de diferentes tradições Javista, Eloísta, Deuteronômica e Sacerdotal ${ }^{1}$ - que refletem cerca de nove séculos de atividade literária hebraica, englobando historiografia, ficção, uma mistura de ambas, listas de leis, profecias tanto em verso como em prosa, obras aforísticas e de meditação, poemas de culto e devoção, hinos de lamentação e vitória, poemas de amor, tábuas genealógicas, contos etiológicos e muito mais. Temos, portanto, uma diversidade de gêneros literários na composição do texto bíblico e que representam os diferentes objetivos e pontos de vistas de seus "autores" (Alter e Kermode, 1997, p. 24.44).

O caráter antológico da literatura deve ser analisado no contexto das sociedades anticoorientais, com as quais Israel mantém relações permanentes em nível cultural, econômico e diplomático. É natural que essa literatura seja permeada de elementos materiais e simbólicos provenientes desse Sitz im Leben, ou contexto, e muitas vezes não se trata de depender mas de compartilhar de um imaginário comum. Podemos dizer que os escritores bíblicos se abeberaram, de vários modos e em vários graus, nas tradições literárias do mundo circunvizinho do Oriente Próximo, mesopotâmico, egípcio, hitita e cananeu (Greenfield, 1977, p. 586). A javeização desse imaginário mítico (Ohler, 1970, p. 7-12) não diminui a força de sua influência sobre a narrativa bíblica.

\section{O imaginário externo}

A atmosfera do Oriente Antigo - e das sociedades antigas como um todo - está permeada de mitos, e é ela que Israel respira. O uso de uma linguagem e de imagens míticas é uma prática comprovada no Antigo Testamento, e, a partir da decifração da literatura mitológica antico-oriental, foi possível identificar as fontes de muitas imagens do AT. Dentre elas podemos destacar: a personificação dos fenômenos naturais (o sol, Sl 19,5-7; a estrela da manhã (Is 14,12ss), a descrição da era escatológica como retorno ao período primitivo, ou à idade de ouro hesíodica (Is 11,6-9); histórias etiológicas ou histórias criadas para explicar uma situação atual, por exemplo, a história da criação da mulher da costela de Adão ( $G n 2,21 \mathrm{ss})$ e aquela da origem da fadiga humana e da dor do parto ( $G n 3,16 \mathrm{ss})$; união dos filhos dos elohim, deuses, e das filhas dos homens ( $G n$ 6,4); a catástrofe universal como retorno ao caos ( $I s$ 17,12ss. 24,19; $J r 4,23$ ); o carro de Javé ( $E z$ 1); imagens teofânicas ( $E x$ 19; 33,19-23). A história do dilúvio (Gn 6,5-9,17 - Pritchard, 1969, p. 42-44.93-95) é uma das mais evidentes afinidades do AT com a literatura extra-bíblica (Mckenzie, 1974, p. 1790-91).

Na maioria das vezes, as dependências imaginárias não são identificadas pelos "autores" dos livros bíblicos e só podem ser conhecidas quando se compara a narrativa bíblica 
com a literatura externa. É o caso, por exemplo, do Salmo 104 (103) que tem uma evidente dependência do "Hino ao Sol" egípcio do período de Akhenaton (1380-1362 a.C.) (Pritchard, 1969, p. 369-71).

Fica, portanto, difícil distinguir no AT entre textos históricos e de ficção, demonstrando que a narrativa bíblica é um texto cheio de significados (Auerbach, 1971) 2 $^{2}$

\section{O imaginário interno}

O imaginário interno trabalha com símbolos envolvendo a própria cultura israelita: pessoas, lugares e eventos ganham dimensões simbólicas que são reproduzidas nas narrações bíblicas em situações diversas daquelas originais em que se inserem geográfica e temporalmente. Isto ocorre não apenas no âmbito do AT, mas também do NT.

O valor simbólico - positivo ou negativo - de um nome bíblico israelita pode ser percebido pelo volume de citações em obras diversas daquela em que é citado "originalmente", e, ocasionalmente, pelo significado diverso daquele original. Dentre os nomes mais expressivos temos:

\begin{tabular}{|c|c|c|}
\hline Nome & texto original & citações \\
\hline Aarão & Ex & Lv; Nm; $1 \mathrm{Cr} ; \mathrm{Sl} ; \mathrm{Hb} ; \mathrm{Lc} ; \mathrm{At}$ \\
\hline Abimelec & $\mathrm{Gn}$ & $\mathrm{Jz} ; 2 \mathrm{Sm} ; 1 \mathrm{Cr} ; \mathrm{Sl}$ \\
\hline Abraão & Gn & $\begin{array}{l}\text { Ex; Lv; Nu; Dt; Js; } 1 \text { Rs; } 2 \text { Rs; } 1 \mathrm{Cr} ; 2 \mathrm{Cr} \text {; Ne; Sl; Is; Jr; Ez; Mq; Mt; } \\
\text { Mc; Lc; At; Rm } 2 \text { Cor; Gl; Hb; Tg; } 1 \text { Pd. }\end{array}$ \\
\hline Ammon & $2 \mathrm{Sm} 13$ & $1 \mathrm{Cr} ; 2 \mathrm{Cr} ; 2 \mathrm{Rs} ; \mathrm{Ne} ; \mathrm{Mt}$ \\
\hline Benjamin & Gn 35,18 & $\begin{array}{l}\text { Ex; Nm; Dt; Js; Jz; } 1 \text { Sm; } 2 \text { Sm; } 1 \text { Rs; } 1 \mathrm{Cr} ; 2 \text { Cr; Esd; Ne; Sl; Is; Ez; } \\
\text { Os; Ab; At; Rm; Fl; Ap }\end{array}$ \\
\hline Davi & $1 \mathrm{Sm}$ & $\begin{array}{l}2 \mathrm{Sm} ; 1 \mathrm{Rs} ; 2 \mathrm{Rs} ; 1 \mathrm{Cr} ; 2 \mathrm{Cr} ; \mathrm{Esd} \text {; Ne; Sl; Pr; Ecl; Ct; Is; Jr; Ez; Os; } \\
\text { Am; Zc; Mt; Mc; Lc; Jo; At; Rm; } 2 \text { Tm; Hb; Ap. }\end{array}$ \\
\hline Jacó & Gn & $\begin{array}{l}\text { Ex; Lv; Nm; Dt; Js;.1 Sm; } 2 \text { Sm; } 1 \text { Rs; } 2 \text { Rs; } 1 \mathrm{Cr} ; \mathrm{Sl} \text {;s; Jr; Lm; Ez; } \\
\text { Os; Am; Ab; Mq; Na; Ml; Mt; Lc; Jo; At; Rm; Hb }\end{array}$ \\
\hline Judá & Gn & $\begin{array}{l}\text { Ex; Nm; Dt; Js; Jz; Rt; } 1 \text { Sm; } 2 \text { Sm; } 1 \text { Rs; } 2 \text { Rs; } 1 \mathrm{Cr} ; 2 \text { Cr; Esd; Ne; } \\
\text { Est; Sl; Is; Jr; Lm; Ez; Dn; Os; Jl; Am; Abd; Mq; Na; Sf; Ag; Zc; Ml; } \\
\text { Hb }\end{array}$ \\
\hline José & Gn & $\begin{array}{l}\text { Ex; Nm; Dt; Js; Jz; } 2 \text { Sm; } 1 \text { Rs; } 1 \text { Cr; Esd; Ne; Sl; Ez; Am; Abd; Zc; } \\
\text { Mt; Mc; Lc; Jo; At; Hb;Ap. }\end{array}$ \\
\hline Israel & Gn & $\begin{array}{l}\text { Ex; Lv; Nm; Dt; Js; Jz; } 1 \text { Sm; } 2 \text { Sm; } 1 \text { Rs; } 2 \text { Rs; } 1 \text { Cr; } 2 \text { Cr; Esd; Ne; } \\
\text { Sl; is; Jr; Lm; Ez; Os; Jl; Am; Mq; Sf; Mt; Lc; Jo; At; Rm; } 1 \text { Cor; } 2 \\
\text { Cor; Gl; Fl; Hb; Ap }\end{array}$ \\
\hline Levi & $\mathrm{Gn}$ & Ex; Nm; Dt; Js; 1 Rs; 1 Cr; Esd; Ne; Ez; Zc; Ml; Mc; Lc; Heb; Ap. \\
\hline $\begin{array}{l}\text { Melquised } \\
c\end{array}$ & Gn & $\mathrm{Sl} ; \mathrm{Ebr}$ \\
\hline Moisés & Ex & $\begin{array}{l}\text { Lv; Nm; Dt; Js; } 1 \text { Rs; } 1 \text { Cr;Sl; Is; Jr; Ml; Mt; Mc; Lc; Jo; At; Rm; } 1 \\
\text { Cor; } 2 \text { Cor; Hb; Jd; Ap. }\end{array}$ \\
\hline Rúbem & Gn & $\mathrm{Ex} ; \mathrm{Nm} ; \mathrm{Dt} ; \mathrm{Js} ; \mathrm{Jz} ; 1 \mathrm{Cr} ; \mathrm{Ez}$ \\
\hline Salomão & $2 \mathrm{Sm}$ & $1 \mathrm{Rs} ; 2 \mathrm{Rs} ; 1 \mathrm{Cr} ; 2 \mathrm{Cr} ; \mathrm{Esd} ; \mathrm{Ne} ; \mathrm{Pr} ; \mathrm{Ct} ; \mathrm{Jr} ; \mathrm{Mt} ; \mathrm{Jo} ; \mathrm{At}$ \\
\hline Samuel & $1 \mathrm{Sm}$ & $1 \mathrm{Cr} ; 2 \mathrm{Cr} ; \mathrm{Sl} ; \mathrm{Jr} ; \mathrm{At} ; \mathrm{Hb}$ \\
\hline Saul & $1 \mathrm{Sm}$ & $2 \mathrm{Sm} ; 1 \mathrm{Cr} ; \mathrm{At}$ \\
\hline
\end{tabular}


Dentre os nomes geográficos se destacam: Basã, Belém, Canaã, Jerusalém, Ramá, Samaria, Sião, Sinai, Horeb, Sodoma, Tiro.

A simbologia dos nomes estrangeiros pode ser detectada, particularmente, quando eles são citados em diferentes obras com significados diversos daquele original, quer seja um nome geográfico ou um adjetivo pátrio. Podemos destacar: Assíria/assírios; Babilônia/ babilônios, Egito/egípcios; Caldéia/caldeus, Líbano, Nínive/ninivitas. Babilônia, por exemplo, "simboliza ao mesmo tempo todos os vícios e todos os abusos dos poderes políticos terrestres" (Le Goff, 1992, p. 306).

O nível simbólico de um texto tende a crescer quando se refere a situações utópicas. A literatura apocalíptica é um claro exemplo dessa tendência. Se os profetas envolvem-se pessoalmente na política palestina, os apocalípticos criam uma dimensão cósmica de luta. Diante de um descrédito com relação às soluções políticas dos problemas de Israel, e da ação histórica de Deus em seu benefício, os apocalípticos - sobretudo os autores do livro de Daniel - criam uma ação imaginária em que Deus venceria o mal em nível cósmico. Para isso utilizam uma linguagem em que quase toda a realidade terrestre ganha um significado simbólico: os olhos simbolizam o conhecimento, as mãos o poder, os cabelos brancos a majestade; a boca o oráculo divino. Aí incluem-se os animais: o leão simboliza a realeza, o boi a força, os animais marinhos o mal, o cordeiro o sacrifício, os chifres dos animais a força, as asas dos pássaros a agilidade (Stuhlmueller, 1974, p. 441).

As visões constituem o principal veículo da apocalíptica e sua compreensão exige uma iniciação em sua simbologia. Um exemplo é a grande visão de Daniel que, apesar de ter Babilônia como cenário (aqui se trata de um exemplo do significado simbólico do termo como vimos acima), refere-se ao período da perseguição de Antíoco Epifanes (167-164 a.C.):

No vigésimo quarto dia do primeiro mês, estando às margens do grande rio, o Tigre,

levantei os olhos para observar. E vi:

Um homem revestido de linho, com os rins cingidos de ouro puro, seu corpo tinha a aparência do crisólito $^{3}$

e seu rosto o aspecto do relâmpago seus olhos como lâmpadas de fogo, seus braços e suas pernas como o fulgor do bronze polido, e o som de suas palavras como o clamor de uma multidão ${ }^{4}$.

Uma outra situação em que emerge o simbolismo é quando um texto que diz respeito a uma situação real que não se verifica passa a fazer parte do imaginário coletivo. É o caso da figura do Emmanuel. O texto de Isaías $(7,1-12,6)$ refere-se a uma grave crise ocorrida durante o governo do rei Acaz - entre 735 e 733 a.C. - e cuja possível solução é atribuída por Isaías ao Emmanuel, possivelmente o filho e sucessor de Acaz, Ezequias. Ao não se verificar essa solução, o texto sobre o Emmanuel continua presente no imaginário coletivo numa perspectiva messiânica. Este Emmanuel de Isaías será identificado por Mateus a Cristo. 
Isaías 7,14

Eis que a jovem ('almah=jovem mulher $)^{5}$ concebeu e dará à luz um filho e por-lhe-ás o nome de Emmanuel

\section{Mateus 1,23}

Eis que a virgem ${ }^{6}$ conceberá e dará à luz um filho e o chamarão com o nome de Emmanuel

Esta interpretação de Mateus será identificada posteriormente com a prática patrística da tipologia, segundo a qual o NT é considerado um midraxe do Antigo, dentro de uma estrutura teológica de promessa e cumprimento (Bruns, 1977, p. 678-79). Nesse caso, todo o Antigo Testamento é considerado uma imagem do Novo.

O evento cristianismo é inserido dentro de um plano imaginário que se torna uma mola propulsora para a difusão e aceitação do evangelho. Jesus Cristo não é apresentado como um personagem isolado mas estreitamente articulado com o imaginário popular de seu ambiente, tomando-se o reino davídico como o modelo do novo "reino de Deus" (cf Mc 11,10) (Romano, 1985, p. 312ss).

No Novo Testamento, além do Apocalipse, uma obra escrita no mesmo gênero do texto de Daniel, é no evangelho de João que, segundo Mateos e Barreto (1979, p. 13-14), encontramos uma narrativa amplamente permeada pelo simbólico. O "autor" preocupa-se menos em relatar jornalisticamente os fatos evangélicos e mais com a representação dos acontecimentos (Everaert-Desmendt, 1984, p. 3), ou seja, com o seu nível simbólico.

A consideração do evangelho joanino como uma narração de caráter puramente histórico resvala em várias dificuldades: "saltos" na topografia, incoerências na sucessão dos fatos e, até mesmo, omissão de dados, falta de lógica narrativa ou detalhes inverossímeis. Por exemplo: Jesus, que estava em Jerusalém, em plena controvérsia com seus adversários, se encontra de repente, sem prévia transição, na Galiléia, à margem oriental do lago, acompanhado de seus discípulos (6,1). No episódio da Ceia (13,1-14,31), de repente no meio de um discurso, Jesus diz "levantai-vos, partamos daqui!" (14,31). Ele, no entanto continua o discurso como se nada tivesse dito (Mateos \& Barreto, 1979, p.13-14). E poderíamos continuar a indicar outros tropeços narrativos.

Uma análise mais coerente da narrativa de João é ver nela uma construção literária ancilla de uma construção teológico-simbólica, onde emergem dois eixos básicos constituídos pelo tema da criação e por aquele da Páscoa-Aliança.

Jesus Cristo é apresentado dentro de um plano cosmogônico, ou seja, sua ação recria o mundo. Para João, Cristo é o Verbo, por meio de quem tudo foi feito (1,2-3) e usa reiteradamente a imagem do "sexto-dia", como o dia da (re)criação do homem: João apresenta Jesus recriando a humanidade.

No que se refere ao tema da Páscoa-Aliança, utiliza muitos símbolos desse binômio histórico-teológico: o cordeiro $(1,29 ; 19,36)$, a lei $(3,1 \mathrm{ss})$, a passagem do mar (6,1: "Depois disso, passou Jesus para a outra margem do mar da Galiléia”), o monte (6,1: o decálogo do monte Sinai utilizado como símbolo do Sermão da montanha); o mundo como inimigo de Jesus e dos seus $(15,18 \mathrm{ss})$ de onde Jesus ou o Pai os tiram/libertam $(15,19 ; 17,6)$ tendo como pano de fundo simbólico a libertação do Egito. 
O episódio da transformação da água em vinho em Caná $(2,1-12)$ envolve tanto o tema da criação quanto aquele da Páscoa-Aliança. Essa transformação pode ser considerada um ato cosmogônico, ou seja uma recriação do homem, tomando a água como símbolo de um homem desfigurado e o vinho como símbolo do homem novo, recriado pela "salvação" crística, e como um gesto que marca o início de um novo êxodo, em que Cristo liberta o homem da opressão do novo Egito (religião judaica institucionalizada) e o conduz para a nova terra prometida

Uma outra imagem forte comentada por Eliade que pode ser encontrada em todo o AT, mas particularmente entre os essênios de Qumrân e no NT, é a da água como símbolo de purificação e de renovação. Assim como as águas do dilúvio que encobriram toda a terra significavam uma renovação de toda a criação, a imersão na água batismal, tanto entre os essênios como entre os cristãos, ao mesmo tempo que constitui um rito de iniciação, repete o gesto cosmogônico. Essa utilização de imagens universais teria facilitado, segundo Eliade a difusão do cristianismo. Assim, uma história local e provinciana torna-se uma história exemplar ao utilizar imagens trans-culturais e trans-temporais" (Eliade, 1952, p. 199203.222).

Concluindo, devemos dizer que uma análise literal da narrativa bíblica dificilmente conseguirá resgatar todo o vigor de seu conteúdo. Mesmo que não possamos atribuir o conceito moderno de autoria aos livros bíblicos, as narrativas têm um alto nível de elaboração, permeadas de sutilezas e de imagens que precisam ser decodificadas para que expressem toda a dimensão de seu significado. A costumeira divisão da escrita prosaica em ficção e não-ficção tem uma aplicação restrita à narrativa bíblica, onde se imbricam o real e o imaginário. Nomes próprios geográficos, israelitas e estrangeiros, elementos cósmicos, números, ganham dimensões supra-racionais prenhes de segundos significados. Isto não significa que a narrativa bíblica deva ser toda interpretada alegoricamente. Littera e semeion não se contradizem, se completam.

A proibição de ícones inibiu fortemente as artes plásticas em Israel, mas não impediu o florescimento da "iconografia" literária.

\section{Notas}

1 - O estudo das tradições que compõem a narrativa bíblica começam com um autor de origem francesa, Jean Astruc, que publica, em 1753, uma obra anônima argumentando que as ocorrências dos nomes divinos Javé e Elohim são características de documentos diversos, teoria essa que iria ser desenvolvida mais tarde por Wellhausen (Die Komposition des Hexateuchs, 187677 e Prolegomena zum Geschichte Israels, 1883). Cf. Rocha, 1990, p. 29.

2 - Apud Alter \& Kermode, 1997, p. 36.

3 - Pedra preciosa da cor do ouro.

4 - Tradução da Bíblia de Jerusalém. S.Paulo: Paulinas, 1985.

5 - Cf. Gesenius, 1976.

6 - Mateus se teria baseado aqui na tradução dos LXX, onde 'almah (jovem mulher) foi traduzido por parthenos. Não obstante este termo ser utilizado na língua grega também com o significado de. jovem mulher/garota (cf. Ilíada 2, 514, Sófocles, Trachiniae 1219), a tradição cristã optou 
pelo significado de "virgem". Em 1110, o exegeta André de S. Vitor sugeriu, em Paris, que a tradução de "“almah" por "virgem" deveria ser corrigida (Cf. Rocha, 1972, p. 20), talvez porque o significado genérico do termo grego parthenos (garota) se tivesse perdido, mantendo-se apenas o significado mais usual de "virgem".

\section{Referências bibliográficas}

ALTER, R. \& KERMODE, F. (Org.). Guia literário da Bíblia. Trad. Raul Fiker. S.Paulo: Editora Unesp, 1997.

BÍBLIA DE JERUSALÉM. S.Paulo: Paulinas, 1985

BROWN, R.E. et al. (Org.). Grande Commentario Biblico. Brescia: Quiriniana, 1974.

BRUNS, G.L. Midraxe e alegoria: os inícios da interpretação escritural. In:ALTER, R. KERMODE, F. (Org.). Guia literário da Bíblia. Trad. Raul Fiker. S.Paulo: Editora Unesp, 1997, p. 667-689.

CARDOSO, Ciro F.C. Iconografia e história. Rio de Janeiro: UFF, s.d. (mimeo).

CHARTIER, R. Imagens. In: BURGUIÈRE, A. Dicionário das Ciências Históricas. Trad. Jayme Salomão. Rio de Janeiro: Imago, 1993, p. 405-408.

ELIADE, Mircea. Images et symboles. Essais sur le symbolisme magico-religieux. Paris: Gallimard, 1952.

EVERAERT-DESMEDT, Nicole. Semiótica da narrativa. Trad. Alice Maria Frias. Coimbra: Livraria Almedina, 1984.

GASKELL, Ivan. História das imagens. In: BURKE, P. A escrita da história. Novas Perspectivas. S.Paulo: Ed. Unesp, 1992, p. 237-271.

GESENIUS, W. A Hebrew and English Lexicon of the Old Testament. Oxford: Clarendon Press, 1976.

GREENFIELD, J. C. A Bíblia hebraica e a literatura cananéia. In: ALTER, R. KERMODE, F. (Org.). Guia literário da Bíblia. Trad. Raul Fiker. S.Paulo: Editora Unesp, 1997, p.585-600.

LE GOFF, J. História e memória. Trad. Bernardo Leitão. Campinas: Ed. Unicamp, 1992.

MATEOS, J. \& BARRETO, J. El evangelio de Juan. Análisis linguístico y comentario exegético. Madri: Ediciones Cristiandad, 1979.

MCKENZIE, J. L. Aspetti del pensiero del Vecchio Testamento. In: BROWN, R.E. et al. (Org.) Grande Commentario Biblico. Brescia: Quiriniana, 1974, p. 1784-1824.

OHLER, A. Elementi mitologici nell'Antico Testamento. Un'indagine storica sui motivi. Turim: Marietti, 1970.

PRITCHARD, J. B. Ancient Near Eastern Texts Relating to the Old Testament. Priceton: Princeton University Press, 1969.

REIS, C. \& LOPES, A. C. M. Dicionário de teoria literária. S.Paulo: Ática, 1988.

ROCHA, Ivan E. A crítica judaica ao helenismo na "sabedoria" de Ben Sirac. São Paulo: USP, 1990. Tese (Doutorado em História Social). Faculdade de Filosofia, Letras e Ciências Humanas, Universidade de São Paulo, 1990. 
ROMANO, Ruggiero (dir). Imaginação social. In: Enciclopédia Einaudi. Trad. Manuel Villaverde Cabral. Lisboa: Imprensa Nacional/Casa da Moeda, 1985, p.287-332.

STUHLMUELLER, C. Il período post-esilico: spirito - apocalittica. In: BROWN, R. E. et al. (Org.) Grande Commentario Biblico. Brescia: Quiriniana, 1974, p. 434-42

VON RAD, G. Eikôn. In: KITTEL, G. (ed.). Grande Lessico del Nuovo Testamento. v. 3, Brescia: Paideia 1967, col. 139-146.

ROCHA, Ivan E. Image and narrative in the Ancient Judaism. Classica, São Paulo, 13/14, p. 251-259, 2000/ 2001.

ABSTRACT: This work presents a reflection about the relationship between image and narrative in the Old Judaism. The iconic prohibition reduced the representation of the characteristics of the Israelite society to the literary documentation. Nevertheless, the images and symbols are present in the narrative and they exercise a fundamental role in the definition of the Israelite culture.

KEYWORDS: Iconography; literature; judaism; Ancient Near East. 